\title{
Os partidos brasileiros na perspectiva dos eleitores: mudanças e continuidades na identificação partidária e na avaliação das principais legendas após 2002
}

\author{
Luciana Fernandes Veiga \\ Universidade Federal do Paraná \\ Doxa/ Instituto Universitário de Pesquisas \\ do Rio de Janeiro
}

\begin{abstract}
Resumo
O artigo analisa as mudanças e continuidades na identidade partidária e na avaliação pelos eleitores dos quatro grandes partidos brasileiros: PT, PMDB, PSDB e PFL/DEM, entre 2002 e 2006. Os dados mostram uma redução no número de eleitores com identificação partidária no período e o PT como a agremiação com a maior perda. Não obstante, nenhum dos três outros partidos foi diretamente beneficiado com a perda petista. Quanto aos perfis dos eleitores de cada partido, a comparação entre os dois pleitos mostra que o PT e o PMDB apresentaram as mudanças mais significativas. A análise final mostra que a avaliação positiva do governo vigente e a avaliação positiva do partido situacionista são as variáveis mais associadas à avaliação dos partidos.
\end{abstract}

Palavras-chave: identidade partidária; avaliação dos partidos; perfil dos eleitores; avaliação do governo

\begin{abstract}
The article analyses the changes and continuities related to the party identification and the party evaluation of the main four Brazilian parties: PT, PMDB,PSDB and PFL/DEM in 2002 and $2006 . \quad$ Data show a reduction in the party identification and the Worker's Party as the one with the main reduction, although none of the other 3 parties have benefited of the reduction. The PMDB and the PT show the most significant changes in the voter's social and demographic characteristics between elections. Finally, the analysis shows that the positive evaluation of the current government and the positive evaluation of the government party are variables strongly associated to the party evaluation.
\end{abstract}

Key words: Party identification; party evaluation; voter's characteristics; government evaluation 
VEIGA, L. F. Os partidos brasileiros na perspectiva dos eleitores: mudanças...

\section{Apresentação}

De acordo com as correntes teóricas do comportamento eleitoral, os eleitores podem construir a sua opinião a respeito dos partidos ao longo do seu processo de socialização política (argumenta a explicação psicológica) ou a partir de sua experiência de classe ou cultural (conforme a explicação sociológica). A partir das imagens que elaboram sobre as legendas, os eleitores tendem, então, a monitorar suas propostas e promessas e, uma vez o partido no poder, eles passam a avaliar o seu desempenho. A expectativa de ganhos futuros com a chegada do partido ao poder e o posterior julgamento de suas realizações estão no cerne da decisão do voto na explicação da teoria da racionalidade. De acordo com Fiorina (1981), esse julgamento da conjuntura vai sendo agregado à imagem das legendas, podendo reforçar ou alterar a postura partidária dos eleitores.

A partir do estudo de Carreirão e Kinzo (2004) sobre a preferência partidária no eleitorado brasileiro no período de 1989 a 2002, é possível visualizar o efeito da conjuntura na avaliação das legendas. Um exemplo citado pelos autores é o caso do PMDB que, entre abril de 1989 e março de 1990, diante do desgaste do governo Sarney, sofreu forte declínio em sua taxa de preferência, reduzida de 19\% para 11\%.

A partir da discussão teórica, busca-se analisar as mudanças e continuidades na identidade partidária e na avaliação que os eleitores fazem dos principais partidos brasileiros após o PT ter assumido a Presidência da República.

Busca-se também tratar de uma questão eminentemente empírica. Até 2002, o PT construiu sua imagem de partido de esquerda e oposicionista. Nos anos anteriores, o PSDB, situacionista por dois mandatos presidenciais consecutivos, vinha deixando de lado a atitude de partido de centro-esquerda e assumia um caráter de legenda de centro-direita. O PMDB estava associado a um ou a outro partido e o PFL aos tucanos. Em estudos anteriores, já foi analisado como o PT e o PSDB alteraram e adaptaram imagem e discurso em sua campanhas eleitorais em 2004 (VEIGA, 2007). Neste artigo, o objetivo é entender como o eleitor assimilou as experiências do PT e do PMDB na situação e os desempenhos do PSDB e do PFL (agora Democratas) na oposição, e como o processamento dessa nova realidade influenciou a sua percepção das legendas.

Para isso, são investigados dois momentos específicos: a eleição presidencial de 2002 e a eleição de 2006. Mais especificamente, este artigo analisa a relação entre partidos e eleitores nos dois pleitos no que se refere à identidade partidária e à avaliação dos partidos, com base nas duas ondas da pesquisa ESEB, 2002 e $2006^{1}$.

\footnotetext{
1 O Projeto ESEB - Estudo Eleitoral Brasileiro é um estudo nacional pós-eleitoral coordenado pelo CESOP/Unicamp e associado ao Comparative Study of Electoral Systems (University of Michigan).
} 


\section{O partido na arena eleitoral}

De acordo com a sistematização das funções das legendas elaborada por Key (1964), pode-se estudar os partidos no eleitorado, os partidos como organizações e os partidos nos governos. As funções dos partidos entre os eleitores seriam educar os cidadãos, mobilizá-los para a participação, criar símbolos para identificação e fidelidade e simplificar a escolha do voto. Enquanto organizações, os partidos deveriam recrutar as lideranças para a ocupação dos governos, treinar a elite política, articular e agregar interesses políticos. Uma vez no governo, os partidos teriam o papel de organizar o governo, atentos à necessidade de criar a sua sustentação com a maioria no Poder Legislativo, organizando os dissidentes e os oposicionistas. Como mandatários, os partidos teriam que pôr em prática suas propostas de políticas públicas, controlar o desempenho da administração e assumir as responsabilidades pelas ações do governo.

Para Dalton e Wattenberg (2002), para educar os cidadãos - primeira função apontada por Key (1964) -, os partidos precisam reduzir o custo da informação, provendo os eleitores com informações importantes e de fácil assimilação. Eles devem ainda propor discussões políticas junto à opinião pública e evidenciar determinados temas, a respeito dos quais também devem se posicionar e justificar sua postura. Os partidos devem envolver os cidadãos no processo eleitoral e motivá-los para o voto, o que pode ser de maneira direta ou indireta. A maneira direta consiste em fazer um apelo para o voto. Já indiretamente, o partido pode investir em despertar ou reforçar a simpatia ou fidelidade entre os eleitores.

Ainda segundo Dalton e Wattenberg (2002), os eleitores precisam de uma âncora política, que os impeça de serem levados por ondas promovidas por líderes demagógicos ou movimentos extremistas. Nesse sentido, os partidos devem criar identificação política a fim de proporcionar um comportamento mais estável entre os eleitores e no sistema democrático. Por fim, para que possa simplificar a escolha dos eleitores - quarta função dos partidos na arena eleitoral de acordo com Key (1964) -, as legendas devem apresentar posições políticas claras e consistentes e ainda informações sobre seus candidatos e temas. Em última instância, os partidos devem buscar a identificação do eleitor com as suas propostas.

\section{A identidade partidária}

A identidade partidária pode ser entendida como uma associação psicológica que as pessoas travam com um partido a partir de suas percepções, valores ou comportamentos (CAMPBELL et al, 1960). Para os precursores da Escola de Michigan, a identidade partidária seria decorrente do processo de socialização 
política dos indivíduos, que resultaria em uma maior afinidade com um partido ou outro.

Ainda de acordo com a corrente psicológica do comportamento político, na medida em que um eleitor se identifica com um partido, ele passa a ver a política a partir da perspectiva partidária. Isso quer dizer que ele tende a se simpatizar mais com os líderes desse partido do que com os das demais legendas, tende a preferir as políticas propostas pela agremiação frente às defendidas pelas demais e, diante de um assunto novo, a respeito do qual ainda não tenha opinião formada, busca se informar sobre a orientação do partido com que tem afinidade. A estabilidade da identidade partidária resultaria dessas posturas.

Fiorina (1981), afinado com Downs (1957) e com seguidores da corrente da escolha racional, propõe que a identidade partidária é um facilitador para a tomada de decisão eleitoral. A identidade é um atalho para que as pessoas decidam o apoio ou a oposição a políticas ou líderes. No entanto, o autor discorda da idéia da identidade partidária como oriunda exclusivamente do processo de socialização política: o eleitor, já em sua fase adulta, ao observar que um partido se comporta em conformidade com os seus interesses, pode acabar se identificando com a legenda, sendo tal processo resultado de uma decisão racional e não simplesmente de uma decisão afetiva, como sugere a corrente psicológica.

Neste artigo, a análise da identidade partidária está feita a partir da perspectiva conceitual adotada por Fiorina (1981). Assim, procura identificar como os eleitores após a experiência com o primeiro mandato do presidente Lula passaram a avaliar os quatro principais partidos. Questiona-se, em última instância, se houve alguma mudança significativa na identidade partidária e na avaliação dos partidos entre os eleitores em decorrência da experiência política do período entre 2002 e 2006.

Além do estudo da identidade partidária, este artigo verifica ainda a avaliação que os eleitores, independentemente de terem alguma identidade partidária, fazem das legendas.

A primeira pergunta a ser respondida é se houve queda do índice de identidade partidária entre 2002 e 2006. Sabe-se que tal taxa vem decaindo em vários países ao longo dos anos. Um estudo de Dalton (2002) sobre o nível de identidade partidária em países desenvolvidos e com sistema democrático estável no período de 1976 a 1992, a partir dos dados da pesquisa Eurobarômetro, aponta para a queda da identidade partidária entre os eleitores a partir dos anos oitenta ${ }^{2}$. De acordo com Dalton e Wattenberg (2002), seriam três as justificativas para a redução da identidade partidária: primeiramente, o vínculo partidário estaria em

\footnotetext{
${ }^{2} \mathrm{O}$ autor trabalha com as democracias estáveis da OECD - Organization of Economic Cooperation and Development.
} 
queda devido a mudanças no perfil do eleitorado, com o aumento da taxa de escolaridade e maior disponibilidade de informações políticas. Ou seja, os indivíduos estariam mais bem informados e, portanto, mais independentes dos partidos para a tomada de decisão. Para os autores, os eleitores estariam vivendo um momento marcado por valores pós-materialistas e portariam novas demandas como desenvolvimento sustentável, escolhas de estilo de vida e outros temas que extrapolam os temas da política.

A crescente influência da mídia sobre o controle da divulgação da informação que antes era repassada à população pelos partidos também estaria contribuindo para o enfraquecimento da relação entre partidos e eleitores. Além disso, as novas técnicas de campanha e de pesquisas de opinião estariam alterando a prática da política, inclusive dentro dos partidos.

Para além das três justificativas apresentadas, Dalton (2002) analisou como a idade e a escolaridade influenciariam a postura do eleitor sobre ter ou não identidade partidária. De acordo com o modelo de Converse, que propõe que a identificação partidária tende a ser menor entre os cidadãos mais novos, o autor encontrou que nas nações de economia avançada e democracia estável a redução da identidade partidária entre os mais jovens é uma realidade (CONVERSE, 1969, apud DALTON, 2002). Em relação à educação, Dalton considerou as ponderações de Campbell et al (1960), que propõe que os eleitores independentes, sem identidade partidária, tendem a estar concentrados em grupos menos envolvidos em política e com menores conhecimento e escolaridade. No entanto, os resultados da pesquisa mostraram que, em seis de cada sete nações pesquisadas, o número de eleitores não partidários vem crescendo fortemente entre os cidadãos com alta escolaridade.

\section{A identidade partidária nas eleições de 2002 e 2006}

Para medir a identidade partidária dos eleitores brasileiros, utilizamos as questões: "Algum partido político representa sua maneira de pensar?" e "Se sim, qual partido melhor representa sua maneira de pensar?"

O percentual de identidade partidária entre os eleitores brasileiros reduziu de $39 \%$ para $28 \%$, ou seja, 11 pontos entre 2002 e 2006 . Entre os quatro grandes partidos, a perda foi mais sentida pelo PT, com a redução da taxa de identidade com a legenda de 23 para 18 pontos. 
Tabela 1 - Identidade partidária, para os eleitores brasileiros, 2002 e 2006

\begin{tabular}{|c|c|c|}
\cline { 2 - 3 } \multicolumn{1}{c|}{} & 2002 & 2006 \\
\hline Não & $56 \%$ & $67 \%$ \\
\hline Sim & $39 \%$ & $28 \%$ \\
\hline Não sabe & $4 \%$ & $4 \%$ \\
\hline $\begin{array}{c}\text { Não } \\
\text { respondeu }\end{array}$ & $1 \%$ & $1 \%$ \\
\hline Total & $100 \%$ & $100 \%$ \\
\hline
\end{tabular}

Fonte: ESEB, 2002, 2006.

Tabela 2 - Partido com o qual tem identidade, para os eleitores brasileiros, 2002 e 2006

\begin{tabular}{|c|c|c|}
\hline Partidos & 2002 & 2006 \\
\hline PT & $23 \%$ & $18 \%$ \\
\hline PMDB & $4 \%$ & $4 \%$ \\
\hline PFL & $2 \%$ & $1 \%$ \\
\hline PSDB & $4 \%$ & $4 \%$ \\
\hline Outros & $6 \%$ & $1 \%$ \\
\hline
\end{tabular}

Fonte: ESEB, 2002, 2006.

A média de idade dos eleitores que se identificam com um dos quatro grandes partidos brasileiros foi reduzida, exceção para os números referentes à identificação partidária com o PT (Tabela 3). Nesse aspecto, o resultado se diferencia daquele encontrado por Dalton (2002) em seu estudo sobre a identidade partidária nos países de democracia estável e economicamente desenvolvidos, nos quais a identidade com as legendas parecia decrescente entre os grupos de eleitores mais novos nos últimos anos. Aqui, a comparação entre os números dos pleitos de 2002 e 2006 aponta que os eleitores partidários do PMDB, PFL e PSDB em 2006 foram acentuadamente mais jovens do que em 2002. O perfil do partidário do PT manteve-se relativamente estável no que se refere à idade. No entanto, se faz necessário destacar que o eleitorado brasileiro em sua totalidade teve a sua idade média reduzida de 40 anos, em 2002, para 39 anos, em 2006. 
Tabela 3 - Média e Mediana para a idade e identidade partidária, segundo partidos, Brasil, 2002 e 2006

\begin{tabular}{|c|c|c|c|c|c|c|c|c|c|c|}
\cline { 2 - 12 } \multicolumn{1}{c|}{} & \multicolumn{2}{c|}{ Total } & \multicolumn{2}{c|}{$P T$} & \multicolumn{2}{c|}{ PMDB } & \multicolumn{2}{c|}{$P F L$} & \multicolumn{2}{c|}{ PSDB } \\
\cline { 2 - 12 } \multicolumn{1}{c|}{} & 2002 & 2006 & 2002 & 2006 & 2002 & 2006 & 2002 & 2006 & 2002 & 2006 \\
\hline Média & 40 & 39 & 37 & 38 & 44 & 39 & 42 & 31 & 40 & 35 \\
\hline Mediana & 37 & 36 & 36 & 36 & 41 & 38 & 35 & 27 & 39 & 28 \\
\hline
\end{tabular}

Teste de independência de médias: Sig 0,006 em 2002 e Sig 0,000 em 2006.

Fonte: ESEB, 2002, 2006

O nível de escolaridade dos eleitores com identidade partidária reduziu entre 2002 e 2006, exceto para os eleitores identificados com o PMDB. O percentual de educação formal decaiu entre aqueles que se identificam com o PFL, o PSDB e, sobretudo, com o PT. Esse fenômeno corrobora o achado de Dalton de que a taxa de escolaridade entre os eleitores partidários vem decaindo, o que aponta para um novo perfil, menos escolarizado.

Tabela 4 - Moda para todos os partidos e escolaridade - 2002 e 2006

\begin{tabular}{|c|c|c|c|c|c|c|c|c|}
\hline & \multicolumn{8}{|c|}{ Escolaridade } \\
\hline & \multicolumn{2}{|r|}{ PT } & \multicolumn{2}{|c|}{ PMDB } & \multicolumn{2}{|r|}{ PFL } & \multicolumn{2}{|c|}{ PSDB } \\
\hline & 2002 & 2006 & 2002 & 2006 & 2002 & 2006 & 2002 & 2006 \\
\hline Moda & $\begin{array}{c}2^{\circ} \\
\text { grau }\end{array}$ & $\begin{array}{c}\text { Analfabeto/ } \\
\text { primário } \\
\text { incompleto }\end{array}$ & $\begin{array}{c}\text { Até } \\
4^{a} \\
\text { série }\end{array}$ & $\begin{array}{c}\text { Ginásio } \\
\text { Incompleto }\end{array}$ & $\begin{array}{c}2^{\circ} \\
\text { grau }\end{array}$ & $\begin{array}{c}\text { Colégio } \\
\text { Incompleto }\end{array}$ & Superior & $\begin{array}{l}\text { Colégio } \\
\text { completo }\end{array}$ \\
\hline
\end{tabular}

Fonte: ESEB, 2002, 2006 
Tabela 5 - Distribuição dos identificados com o PT por faixa de escolaridade 2002 e 2006

\begin{tabular}{|c|c|c|c|c|c|c|}
\hline & \multicolumn{3}{|c|}{2002} & \multicolumn{3}{|c|}{2006} \\
\hline \multirow{10}{*}{ PT } & & $\%$ & $\begin{array}{c}\% \\
\text { Acumulado } \\
\end{array}$ & & $\%$ & $\begin{array}{c}\% \\
\text { Acumulado } \\
\end{array}$ \\
\hline & Sem instrução & 3 & 3 & $\begin{array}{c}\text { Analfabeto/Primário } \\
\text { incompleto }\end{array}$ & 24 & 24 \\
\hline & Até $4^{a}$. série & 19 & 22 & Primário completo & 16 & 40 \\
\hline & $\begin{array}{c}\text { De } 5^{\mathrm{a}} \cdot \text { A } 8^{\mathrm{a}} . \\
\text { Série } \\
\end{array}$ & 20 & 42 & Ginásio incompleto & 15 & 55 \\
\hline & $2^{\circ}$. Grau & 41 & 83 & Ginásio completo & 10 & 65 \\
\hline & $\begin{array}{c}\text { Superior ou } \\
\text { mais }\end{array}$ & 17 & 100 & Colégio incompleto & 12 & 77 \\
\hline & Total & 100 & & Colégio completo & 17 & 95 \\
\hline & & & & $\begin{array}{l}\text { Universitário } \\
\text { Incompleto }\end{array}$ & 5 & 99 \\
\hline & & & & $\begin{array}{c}\text { Universitário } \\
\text { completo ou mais }\end{array}$ & 1 & 100 \\
\hline & & & & Total & 100 & \\
\hline
\end{tabular}

Teste de independência (Teste do Chi-Square): Sig. 0,000 em 2002 e 2006.

Fonte: ESEB, 2002, 2006.

O valor da renda familiar entre os eleitores que se identificam com o PMDB no período entre 2002 e 2006 cresceu acentuadamente. No caso do PFL, a renda média dos eleitores que se identificam com a legenda sofreu pequena alteração. No entanto, a variação da mediana foi acentuada, apontando para uma distribuição de renda mais uniforme dentro do grupo em 2006. O valor da renda manteve-se relativamente estável entre os eleitores que se identificam com o PSDB. Por fim, houve uma queda abrupta na média da renda familiar daqueles que se identificam com o PT. 
Tabela 6 - Média da renda familiar (em Reais), por identidade partidária, Brasil, 2002 e 2006.

\begin{tabular}{|c|c|c|c|}
\cline { 3 - 4 } \multicolumn{2}{c|}{} & 2002 & 2006 \\
\hline \multirow{2}{*}{ PT } & Média & $1.349,63$ & 985,08 \\
\cline { 2 - 4 } & Mediana & 800,00 & 746,94 \\
\hline \multirow{2}{*}{ PFL } & Média & 660,83 & $1.053,19$ \\
\cline { 2 - 4 } & Mediana & 400,00 & 900,00 \\
\cline { 2 - 4 } & Média & 969,26 & 946,47 \\
\hline \multirow{2}{*}{ PSDB } & Mediana & 500,00 & $1.060,56$ \\
\cline { 2 - 4 } & Média & $1.867,08$ & $1.788,12$ \\
\hline & Mediana & $1.200,00$ & $1.233,46$ \\
\hline
\end{tabular}

Teste de independência de médias: Sig 0,000 em 2002 e Sig 0,005 em 2006. Os resultados dos testes apontam que há diferenças significativas no que se refere às médias de renda familiar e a distribuição da identidade partidária entre as diversas legendas. No entanto, não podemos afirmar se a diferença é significativa na distribuição entre todos ou apenas entre um partido e os demais.

Fonte: ESEB, 2002, 2006.

Quanto à distribuição da identidade partidária segundo as regiões do país, constatou-se o enfraquecimento da identidade partidária dos eleitores com o PT no sudeste e o seu fortalecimento junto ao nordeste, norte e centro-oeste. Por sua vez, o índice de identidade dos eleitores com o PMDB caiu no nordeste e cresceu no sul do país. Movimento parecido ocorreu para o PSDB, que teve a taxa de identidade reduzida entre os eleitores do nordeste e sudeste e crescente na região sul. A nova configuração da distribuição das identidades partidárias pode estar apontando para mudanças nos embates regionais. Ademais, as alianças entre PT e PMDB, de um lado, e PFL e PSDB, de outro, parecem ser complementares se pensadas a partir da distribuição da identidade partidária nas regiões. 
Tabela 7 - Região em que mora, segundo identidade partidária (\%) - 2002 e 2006

\begin{tabular}{|c|c|c|c|}
\hline Partido & Região & 2002 & 2006 \\
\hline \multirow{5}{*}{ PT } & Nordeste & 22 & 32 \\
\hline & $\begin{array}{c}\text { Norte /Centro- } \\
\text { Oeste }\end{array}$ & 8 & 14 \\
\hline & Sudeste & 58 & 42 \\
\hline & Sul & 12 & 12 \\
\hline & Total & 100 & 100 \\
\hline \multirow{5}{*}{ PMDB } & Nordeste & 31 & 13 \\
\hline & $\begin{array}{c}\text { Norte /Centro- } \\
\text { Oeste }\end{array}$ & 12 & 17 \\
\hline & Sudeste & 38 & 36 \\
\hline & Sul & 19 & 34 \\
\hline & Total & 100 & 100 \\
\hline \multirow{5}{*}{ PFL } & Nordeste & 46 & 94 \\
\hline & $\begin{array}{c}\text { Norte /Centro- } \\
\text { Oeste }\end{array}$ & 9 & 0 \\
\hline & Sudeste & 33 & 0 \\
\hline & Sul & 12 & 6 \\
\hline & Total & 100 & 100 \\
\hline \multirow{5}{*}{ PSDB } & Nordeste & 23 & 15 \\
\hline & $\begin{array}{c}\text { Norte /Centro- } \\
\text { Oeste }\end{array}$ & 9 & 11 \\
\hline & Sudeste & 61 & 52 \\
\hline & Sul & 7 & 23 \\
\hline & Total & 100 & 100 \\
\hline
\end{tabular}

Teste de independência de médias: Sig 0,001 em 2002 e Sig 0,000 em 2006. Os resultados dos testes apontam que há diferenças significativas no que se refere à distribuição da identidade partidária entre as diversas legendas e as regiões. No entanto, não podemos afirmar se a diferença é significativa entre todos ou apenas entre um partido e os demais.

Fonte: ESEB, 2002, 2006.

Em relação ao posicionamento ideológico, os eleitores que se identificam com o PT continuam se apresentando mais à esquerda, embora tenha havido uma "centralização" desse segmento. Em 2006, o PT, na média, representou um eleitorado mais de centro do que em 2002.

A mudança mais brusca foi sentida na auto-localização dos eleitores que se identificam com o PFL. Em 2006, o perfil dos eleitores que se identificavam com o partido esteve fortemente associado à direita (média 8,5), diferentemente de 2002 
$(6,1)$. Outra mudança significativa deu-se com a identificação com o PMDB. Os eleitores que demonstravam identidade com o partido em 2002 estavam consideravelmente mais à direita do que em 2006.

Tabela 8 - Auto-localização pelo eleitor na escala esquerda (0) e direita(10) e identidade por partido - 2002 e 2006.

\begin{tabular}{|c|c|c|c|}
\hline & & 2002 & 2006 \\
\hline \multirow{3}{*}{ PT } & Média & 4,7 & 5,5 \\
\hline & Mediana & 5,0 & 5,0 \\
\hline & $\begin{array}{l}\text { Desvio } \\
\text { padrão }\end{array}$ & 3,6 & 3,4 \\
\hline \multirow{3}{*}{ PMDB } & Média & 8,3 & 6,3 \\
\hline & Mediana & 10,0 & 5,0 \\
\hline & $\begin{array}{l}\text { Desvio } \\
\text { Padrão }\end{array}$ & 2,7 & 2,3 \\
\hline \multirow{3}{*}{ PFL } & Média & 6,1 & 8,5 \\
\hline & Mediana & 8,0 & 10,0 \\
\hline & $\begin{array}{l}\text { Desvio } \\
\text { Padrão } \\
\end{array}$ & 3,9 & 3,4 \\
\hline \multirow{3}{*}{ PSDB } & Média & 6,5 & 5,7 \\
\hline & Mediana & 8,0 & 6,0 \\
\hline & $\begin{array}{l}\text { Desvio } \\
\text { Padrão }\end{array}$ & 3,3 & 3,4 \\
\hline
\end{tabular}

Fonte: ESEB, 2002, 2006

Os resultados da análise de correspondência desenvolvida para averiguar a relação entre a auto-localização ideológica e a identificação com os partidos entre os eleitores ${ }^{3}$ apontam que a correspondência entre a auto-localização ideológica e a identificação com os partidos ocorreu apenas em 2002 (Sig. 0,000). Em 2006, não foi possível identificar correspondência entre as categorias (Sig.0, 214). Nesta eleição, a identificação com o PT perpassou as diferentes clivagens ideológicas do eleitorado.

\footnotetext{
${ }^{3}$ A Análise Fatorial de Correspondência visa estruturar estatisticamente uma agregação de variáveis em conjuntos de eixos fatoriais que tenham componentes relacionais, procurando encontrar aqueles que possam traduzir uma associação otimizada das categorias relevantes. Por meio da estatística do Qui. Quadrado, testa-se a hipótese da independência entre linha e coluna. No caso da rejeição da hipótese nula, procura-se ajustar linha e coluna, ordenando e operando uma escala de intervalos que permita definir os eixos fatoriais e as posições relativas das categorias (SILVA, 2003).
} 
Gráfico 1 - Auto-localização ideológica e identidade partidária, 2002

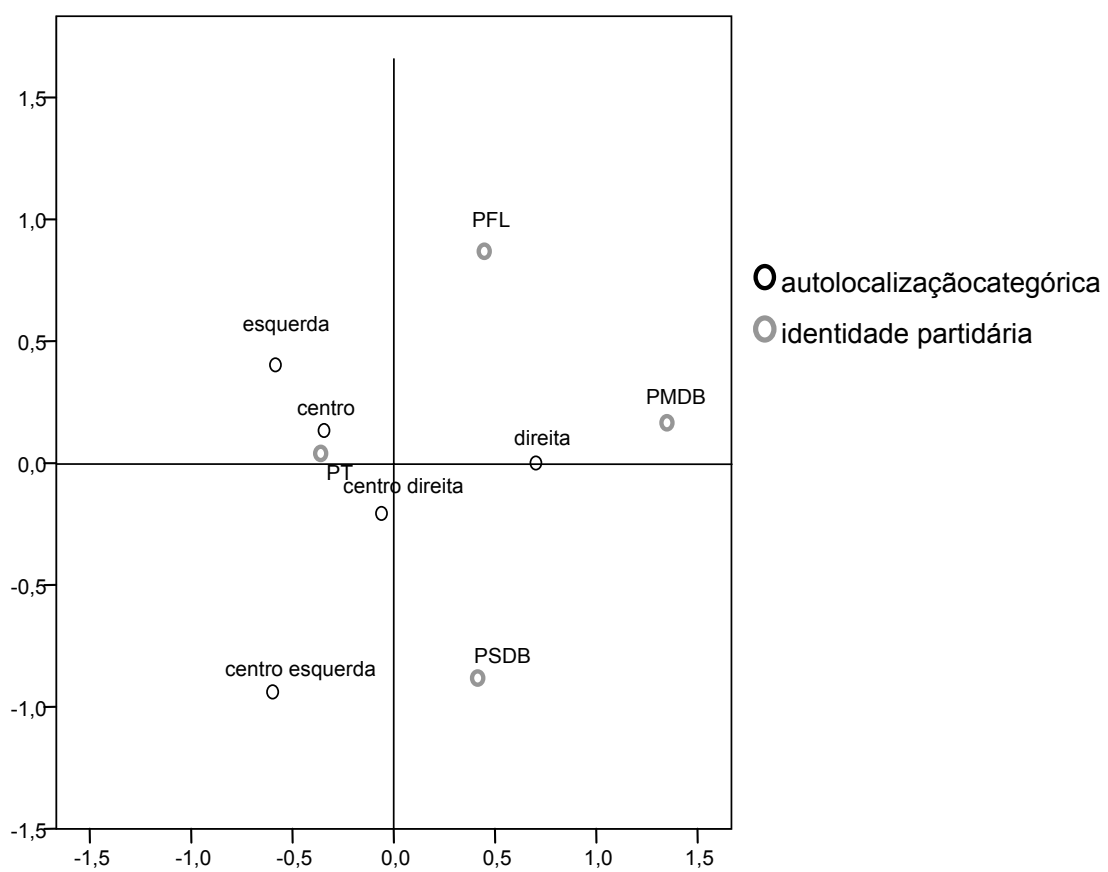

Gráfico 2 - Auto-localização ideológica e identidade partidária, 2006

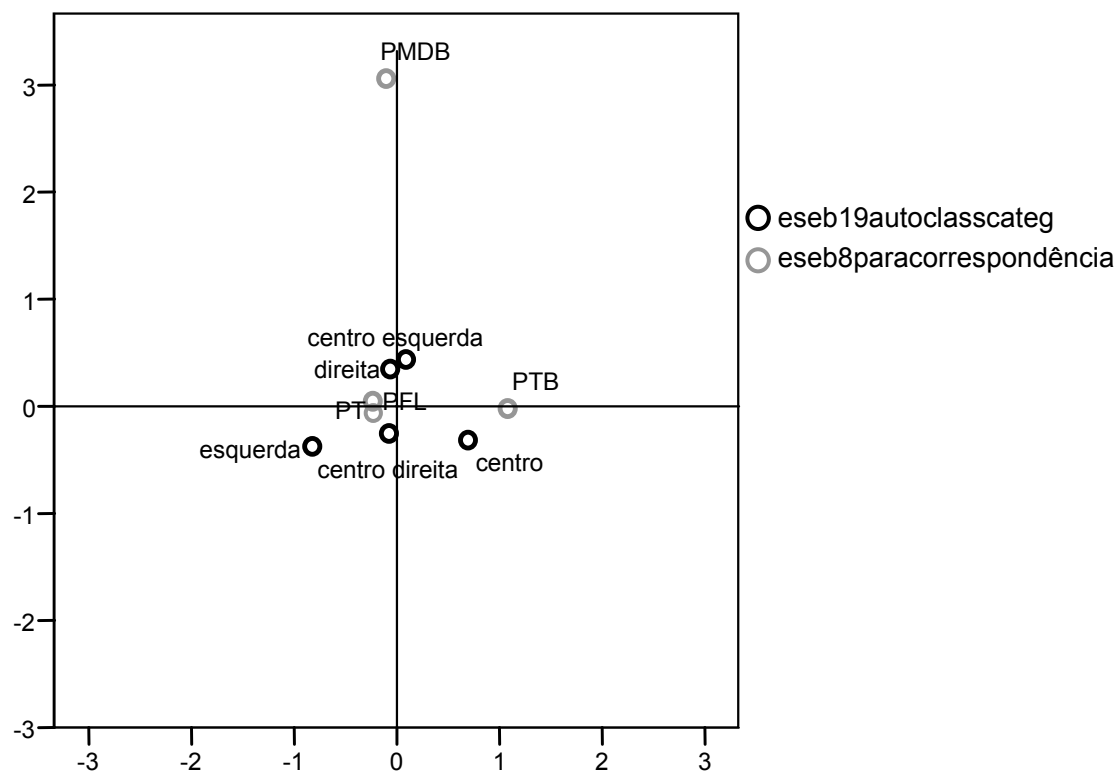


Por fim, buscou-se elaborar uma análise de correspondência a fim de verificar a relação entre satisfação com o governo vigente - Fernando Henrique em 2002 e Lula em 2006 - e a identidade partidária. Nos dois anos, foi possível identificar a correspondência (Sig. 0,000). Como demonstram as figuras, havia um forte alinhamento entre os satisfeitos com o governo Fernando Henrique e os eleitores que se identificavam com o PSDB e, no sentido contrário, forte ligação entre insatisfeitos e identificados com o PT. Em 2006, é notória a correspondência entre os eleitores insatisfeitos com o governo Lula e os identificados com o PSDB e ainda a correspondência entre os eleitores satisfeitos com o governo e com identificação com o PT.

Gráfico 3 - Avaliação de governo e identidade partidária, 2002

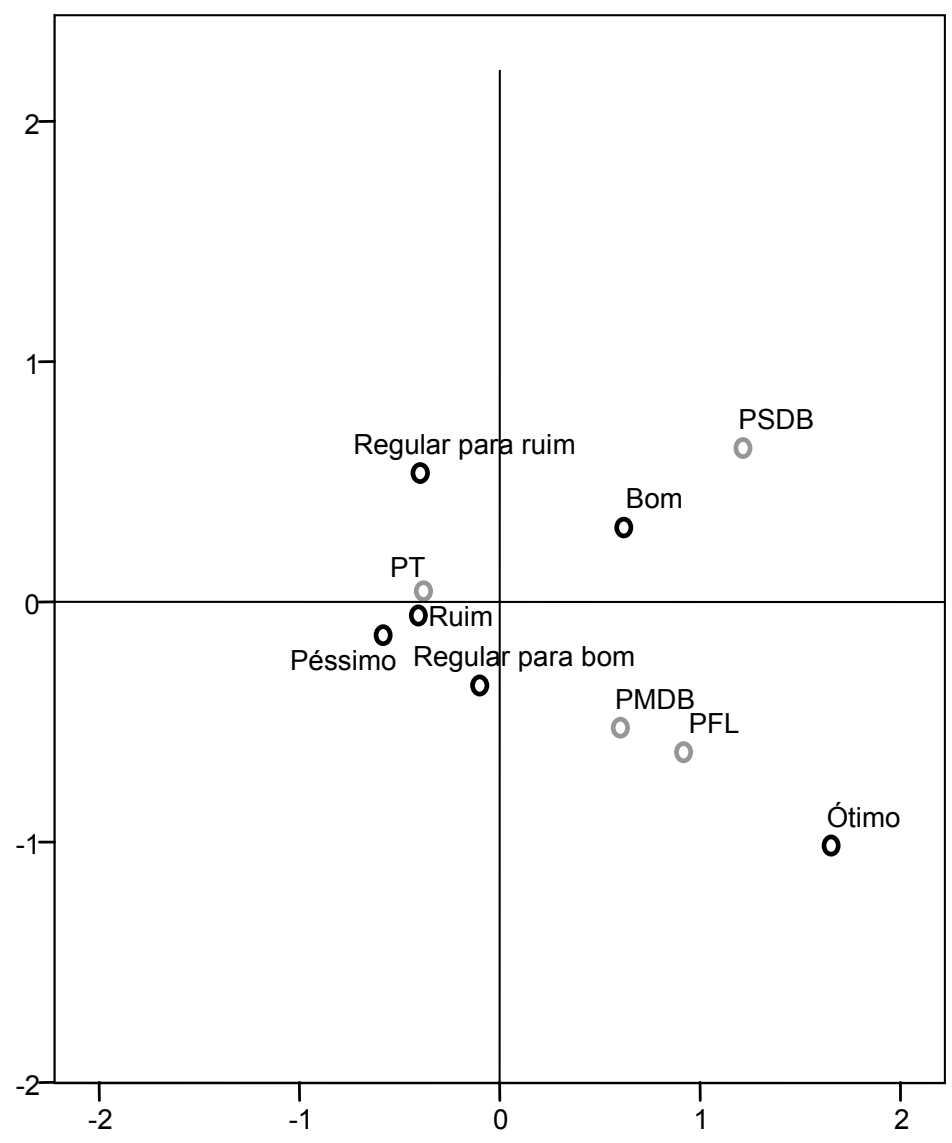

Avaliação do Governo O Fernando Henrique nos últimos 4 anos

Oidentidadepartidária 
Gráfico 4 - Avaliação de governo e identidade partidária, 2006

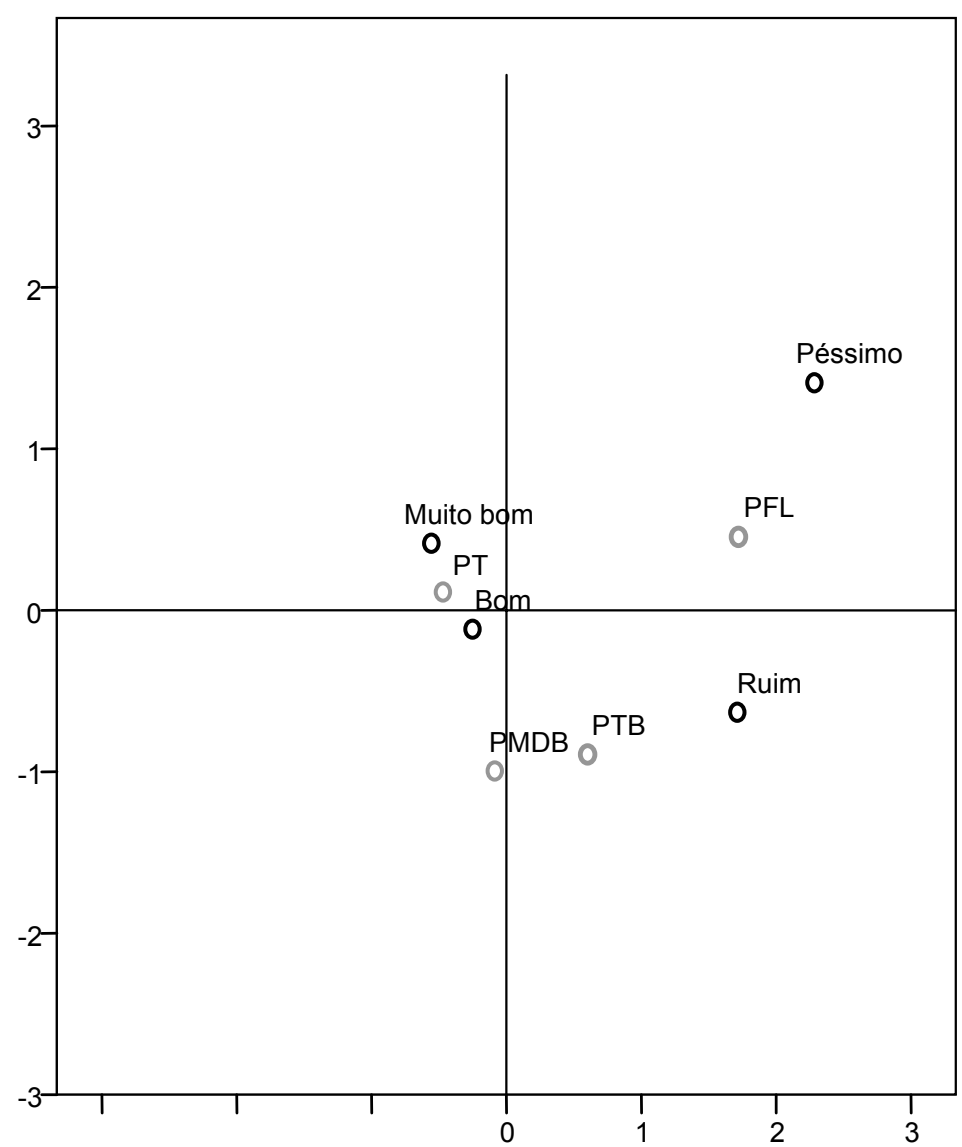

ESEB6) Na sua opinião, de uma maneira geral o Governo

Lula nos últimos 4 anos foi.... eseb8paracorrespondencia

4. Avaliação dos partidos pelos eleitores nas eleições de 2002 e 2006

Quando analisamos as variáveis com influência sobre a avaliação partidária pelos eleitores comuns - independente de ter ou não identidade partidária -, encontramos que o PT continua sendo o partido mais bem avaliado. Em 2002, o partido recebeu dos eleitores a nota média 6,0; em 2006, após a experiência do primeiro mandato do presidente Lula, a avaliação caiu para 4,7, mas, ainda assim, ele permanece como o partido mais bem conceituado

Uma análise da correlação entre idade e avaliação do PT e, a seguir, a correlação entre renda familiar e avaliação do partido mostram que as variáveis independentes estão correlacionadas com a avaliação do partido, mas que a 
alteração em qualquer uma delas não é capaz de promover mudanças relevantes na avaliação do PT ${ }^{4}$.

Apenas para 2002 foi verificada a existência da correlação entre a autoclassificação do eleitor na escala esquerda-direita e a avaliação do partido. Naquele ano, de acordo com o coeficiente de Beta, conforme crescia em um ponto a autolocalização do eleitor na escala da esquerda (0) para a direita (10), diminuía em 0,150 pontos a avaliação do PT. De novo, os números são pouco expressivos.

Em 2002 e em 2006, foi possível verificar correlação entre a avaliação da imagem do partido entre esquerda e direita e a avaliação do partido. Em 2002, conforme crescia em um ponto a classificação que o eleitor fazia do partido na escala de esquerda (0) e direita (10), aumentava em 0,292 a avaliação do PT. Já em 2006, conforme crescia em um ponto a classificação que o eleitor fazia do partido na escala esquerda (0) e direita (10), aumentava em 0,354 pontos a avaliação do PT. Ou seja, quanto mais o partido é tido como de centro, melhor a avaliação da legenda pelos eleitores.

Tabela 9 - Avaliação do PT segundo variáveis específicas em 2002 e 2006

\begin{tabular}{|c|c|c|c|c|c|}
\hline \multicolumn{6}{|c|}{ PT } \\
\hline \multirow{5}{*}{2002} & Regressão linear & $\begin{array}{c}\mathrm{R} \\
\text { (Correlação) }\end{array}$ & $\begin{array}{c}\mathrm{R} \\
\text { Quadrado }\end{array}$ & $\begin{array}{l}\text { Anova } \\
\text { (Sig.) }\end{array}$ & CoeficienteBeta \\
\hline & Idade & 0,091 & 0,008 & 0,000 & $.0,021$ \\
\hline & Renda Familiar & 0,094 & 0,009 & 0,000 & 0,000 \\
\hline & Ideologia & 0,142 & 0,020 & 0,000 & $.0,150$ \\
\hline & $\begin{array}{c}\text { Avaliação/Imagem } \\
\text { partido(esq/dir) }\end{array}$ & 0,292 & 0,085 & 0,000 & 0,292 \\
\hline \multicolumn{6}{|c|}{ PT } \\
\hline \multirow{5}{*}{2006} & Regressão linear & $\begin{array}{c}\mathrm{R} \\
\text { (Correlação) }\end{array}$ & $\begin{array}{c}\mathrm{R} \\
\text { Quadrado }\end{array}$ & $\begin{array}{l}\text { Anova } \\
\text { (Sig.) }\end{array}$ & CoeficienteBeta \\
\hline & Idade & 0,085 & 0,007 & 0,009 & 0,018 \\
\hline & Renda Familiar & 0,132 & 0,017 & 0,004 & 0,000 \\
\hline & Ideologia & 0,013 & 0,000 & 0,752 & $.0,016$ \\
\hline & $\begin{array}{c}\text { Avaliação/Imagem } \\
\text { partido(esq/dir) }\end{array}$ & 0,340 & 0,115 & 0,000 & 0,354 \\
\hline
\end{tabular}

Fonte: ESEB, 2002, 2006

\footnotetext{
${ }^{4}$ A medida da correlação varia entre 1 e 1: quanto mais próximo dos extremos maior a correlação entre as variáveis, podendo ser negativa ou positiva. Valor igual a zero ou perto de zero significa que não existe relação entre a distribuição das variáveis ou que ela é muito fraca.
} 
Os dados mostram que há correspondência entre a avaliação do governo vigente e a avaliação do PT (Sig. 0,000 para os dois momentos). Em 2002, os eleitores que avaliavam o governo FHC de maneira positiva tendiam a não gostar do PT. Correspondência semelhante foi identificada entre os eleitores que achavam o governo FHC ótimo e desgostavam muito do PT. Em 2006, os eleitores que avaliavam o governo Lula de maneira negativa tendiam a não gostar do PT.

Gráfico 5 - Avaliação de governo e avaliação do PT, 2002

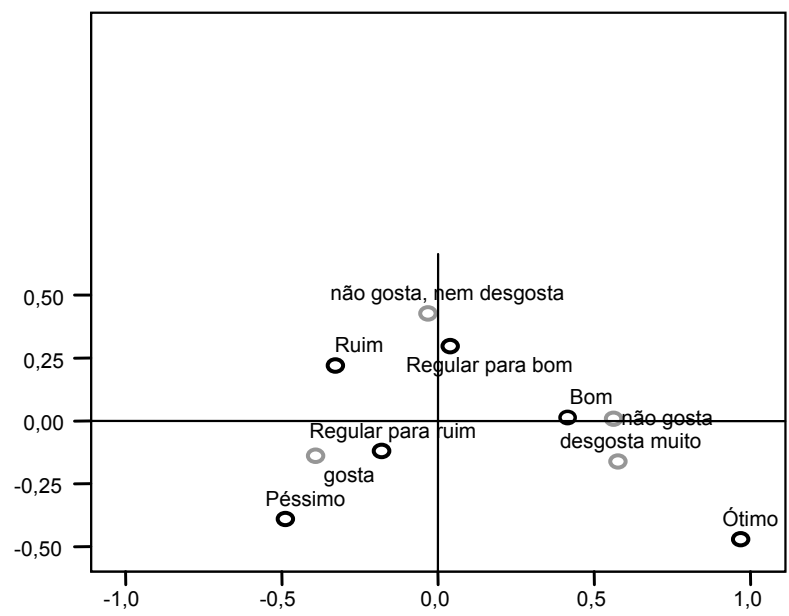

Avaliação do Governo

O Fernando Henrique nos últimos 4 anos

gostarPTcat

Gráfico 6 - Avaliação de governo e avaliação do PT, 2006

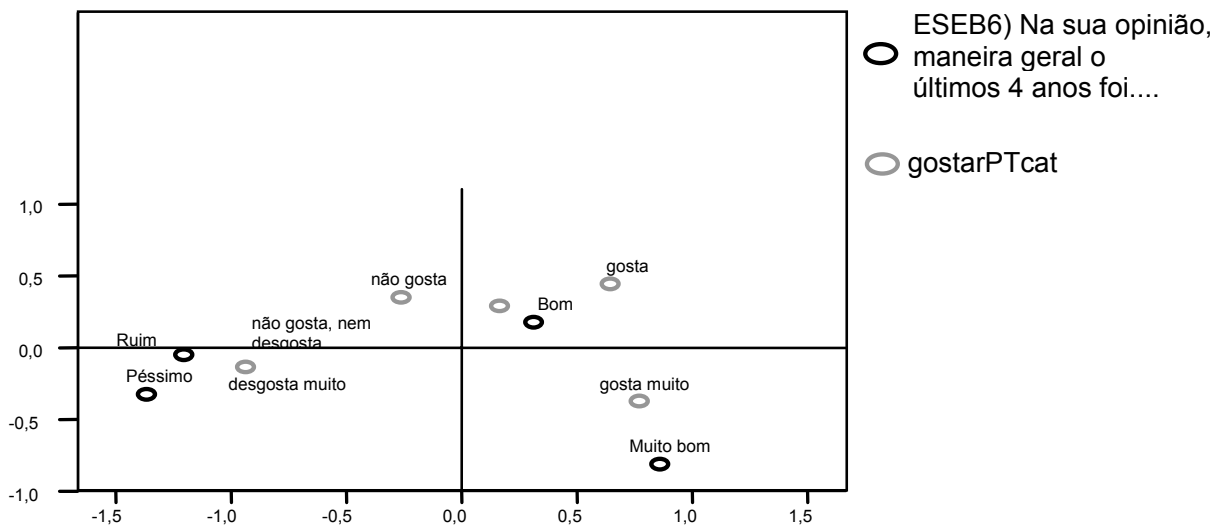


A análise do PSDB mostrou que o reflexo das alterações na idade ou no valor da renda familiar dos eleitores sobre a avaliação do partido não pode ser afirmado (Sig.> 0,05) e o mesmo ocorre para a correlação entre essas variáveis e a avaliação do partido.

Já no que se refere à ideologia do eleitor e à imagem do partido na escala esquerda (0) e direita (10), constata-se que há correlação entre as variáveis e a avaliação do partido. Em relação ao grau de predição, pode-se dizer que, em 2002, conforme crescia em um ponto a classificação que o eleitor fazia do partido na escala esquerda (0) e direita (10), aumentava em 0,207 pontos a avaliação do PSDB. Já em 2006, o acréscimo era de 0,130 pontos na avaliação do partido para cada aumento de um ponto na escala da imagem do partido.

Tabela 10 - Avaliação do PSDB segundo variáveis específicas em 2002 e 2006

\begin{tabular}{|c|c|c|c|c|c|}
\hline \multicolumn{6}{|c|}{$P S D B$} \\
\hline \multirow{5}{*}{2002} & Regressão linear & $\begin{array}{c}\mathrm{R} \\
\text { (Correlação) }\end{array}$ & $\begin{array}{c}\text { R } \\
\text { Quadrado }\end{array}$ & $\begin{array}{l}\text { Anova } \\
\text { (Sig.) }\end{array}$ & Coeficiente Beta \\
\hline & Idade & 0,31 & 0,001 & 0,167 & 0,006 \\
\hline & Renda Familiar & 0,017 & 0,000 & 0,467 & 2,99E-005 \\
\hline & Ideologia & 0,207 & 0,043 & 0,000 & 0,190 \\
\hline & $\begin{array}{c}\text { Avaliação/Imagem } \\
\text { partido (esq/dir) }\end{array}$ & 0,213 & 0,045 & 0,000 & 0,207 \\
\hline \multicolumn{6}{|c|}{$P S D B$} \\
\hline \multirow{5}{*}{2006} & Regressão linear & $\begin{array}{c}\mathrm{R} \\
\text { (Correlação) }\end{array}$ & $\begin{array}{c}\mathrm{R} \\
\text { Quadrado }\end{array}$ & $\begin{array}{l}\text { Anova } \\
\text { (Sig.) }\end{array}$ & Coeficiente Beta \\
\hline & Idade & 0,015 & 0,000 & 0,666 & $.0,003$ \\
\hline & Renda Familiar & 0,073 & 0,005 & 0,126 & 0,000 \\
\hline & Ideologia & 0,111 & 0,012 & 0,009 & 0,115 \\
\hline & $\begin{array}{l}\text { Avaliação/Imagem } \\
\text { partido (esq/dir) }\end{array}$ & 0,140 & 0,020 & 0,001 & 0,130 \\
\hline
\end{tabular}

Fonte: ESEB, 2002, 2006.

No pleito de 2006, no que se refere à correspondência entre a avaliação de governo e a avaliação do PSDB, o resultado mostrou-se estatisticamente não significativo (Sig 0,154); no pleito anterior, fora possível detectar a associação entre avaliar bem o governo Fernando Henrique e a avaliação positiva do PSDB. A nota média do partido foi 4,2 em 2002 e 3,5 em 2006. 
Gráfico 7 - Avaliação de governo e avaliação do PSDB, 2002

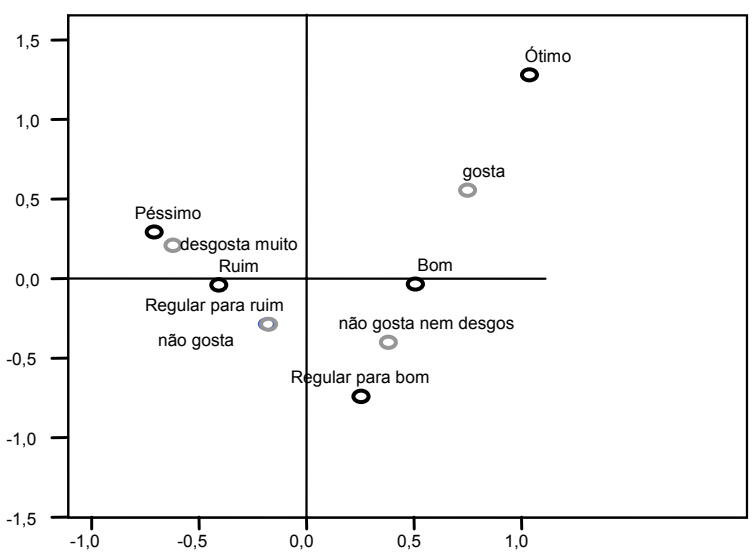

Avaliação do Governo Fernando

OHenrique nos últimos 4 anos

gostarPSDBcat

Quando analisamos o PMDB em 2002, as variáveis que apresentaram maior índice de correlação com a avaliação partidária foram a ideologia do eleitor e a avaliação da imagem do partido na escala da esquerda para a direita. Em relação ao grau de predição, conforme crescia em um ponto a auto-localização do eleitor na escala ideológica (esquerda-direita), havia um aumento de 0,259 pontos na avaliação do partido. De modo similar, conforme crescia em um ponto a percepção do eleitor sobre a classificação do partido no espectro esquerda e direita, havia um acréscimo de 0,321 pontos na possibilidade de identidade com o PMDB. Já em 2006, não foi detectada a correlação entre a imagem do partido e a avaliação do partido.

Tabela 11 - Avaliação do PMDB segundo variáveis específicas em 2002 e 2006

\begin{tabular}{|c|c|c|c|c|c|}
\hline \multicolumn{7}{|c|}{$P M D B$} \\
\hline \multirow{4}{*}{2002} & Regressão linear & R (Correlação) & R Quadrado & Anova(Sig.) & Coeficiente Beta \\
\cline { 2 - 6 } & Idade & 0,047 & 0,002 & 0,031 & 0,010 \\
\cline { 2 - 6 } & Renda Familiar & 0,100 & 0,010 & 0,000 & 0,000 \\
\cline { 2 - 6 } & Ideologia & 0,264 & 0,069 & 0,000 & 0,259 \\
\cline { 2 - 7 } & $\begin{array}{c}\text { Avaliação/Imagem } \\
\text { partido(esq/dir) }\end{array}$ & 0,300 & 0,090 & 0,000 & 0,321 \\
\hline
\end{tabular}




\begin{tabular}{|c|c|c|c|c|c|}
\hline \multicolumn{1}{|c|}{$P M D B$} \\
\hline \multirow{4}{*}{2006} & Regressão linear & R(Correlação) & R Quadrado & Anova(Sig.) & Coeficiente Beta \\
\cline { 2 - 6 } & Idade & 0,024 & 0,001 & 0,472 & 0,004 \\
\cline { 2 - 6 } & Renda Familiar & 0,052 & 0,003 & 0,274 & 0,000 \\
\cline { 2 - 6 } & Ideologia & 0,117 & 0,014 & 0,006 & 0,119 \\
\cline { 2 - 6 } & $\begin{array}{c}\text { Avaliação/Imagem } \\
\text { partido(esq/dir) }\end{array}$ & 0,054 & 0,003 & 0,209 & 0,056 \\
\hline
\end{tabular}

Fonte: ESEB 2002, 2006.

Para a correspondência entre avaliação de governo e avaliação do PMDB, o resultado obtido foi estatisticamente significativo nos pleitos de 2002 e de 2006 (Sig.0,000 e Sig. 0,005). Foi possível detectar uma associação entre avaliar bem o governo Fernando Henrique e a avaliação positiva do partido em 2002, e entre avaliar bem o governo Lula e a avaliação positiva do PMDB em 2006.

Gráfico 8 - Avaliação de governo e avaliação do PMDB, 2002

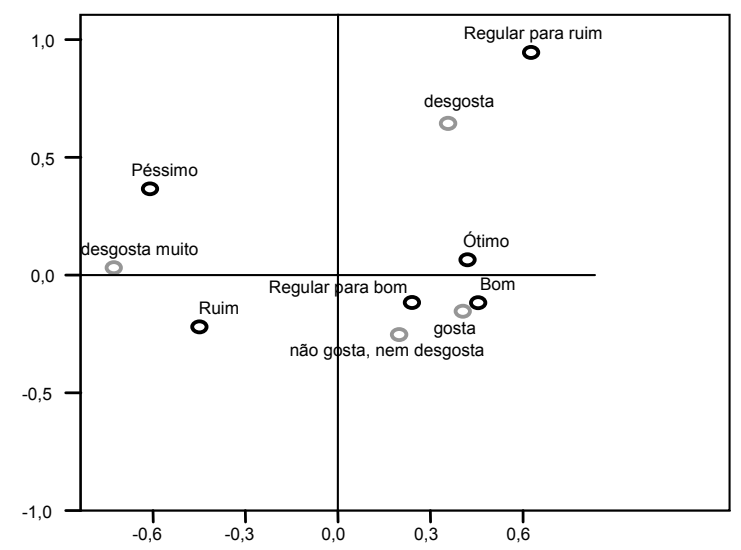
Avaliação do Governo
Fernando Henrique nos últimos 4 anos

gostaPMDBcat 


\section{Gráfico 9 - Avaliação de governo e avaliação do PMDB, 2006}

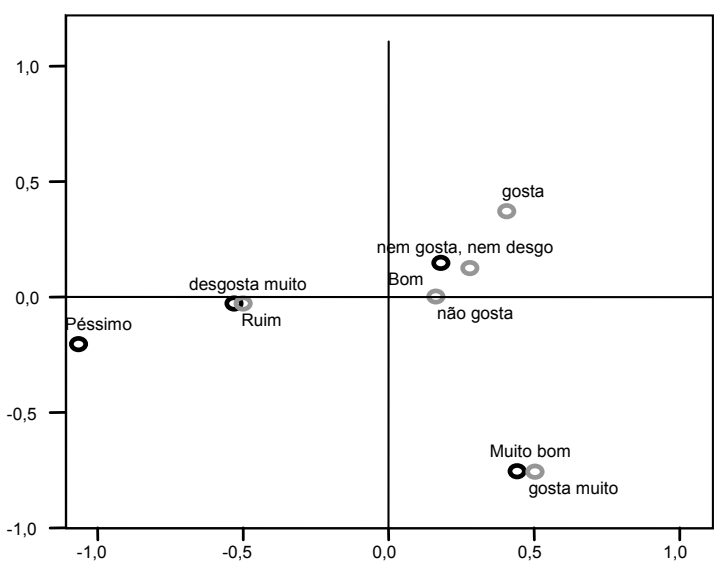

ESEB6) Na sua opinião, O uma maneira

Governo Lula nos últimos

4 anos foi....

gostarPMDBcat

Finalmente, para o PFL (agora Democratas), os dados mostram que alterações na idade, na renda familiar, na ideologia do eleitor ou na avaliação da imagem do partido (esquerda/direita) repercutiram de maneira linear na avaliação da legenda em 2002. No entanto, a relação das variáveis com a avaliação da legenda demonstrou-se muito fraca, exceto para a ideologia do eleitor. Em 2006, apenas a ideologia do eleitor esteve correlacionada com a avaliação do PFL.

Tabela 12 - Avaliação do PFL segundo variáveis específicas em 2002 e 2006

\begin{tabular}{|c|c|c|c|c|c|}
\hline \multicolumn{6}{|c|}{$P F L$} \\
\hline \multirow{5}{*}{2002} & Regressão linear & $\mathrm{R}$ (Correlação) & $\begin{array}{c}\mathrm{R} \\
\text { Quadrado }\end{array}$ & $\begin{array}{l}\text { Anova } \\
\text { (Sig.) }\end{array}$ & Coeficiente \\
\hline & Idade & 0,058 & 0,003 & 0,010 & 0,012 \\
\hline & Renda Familiar & 0,101 & 0,010 & 0,000 & 0,000 \\
\hline & Ideologia & 0,277 & 0,077 & 0,000 & 0,258 \\
\hline & $\begin{array}{c}\text { Avaliação/Imagem } \\
\text { partido(esq/dir) }\end{array}$ & 0,112 & 0,013 & 0,001 & 0,109 \\
\hline \multicolumn{6}{|c|}{$P F L$} \\
\hline \multirow{5}{*}{2006} & Regressão linear & $\mathrm{R}$ (Correlação) & $\begin{array}{c}\mathrm{R} \\
\text { Quadrado }\end{array}$ & $\begin{array}{c}\text { Anoval } \\
\text { Sig.) }\end{array}$ & Coeficiente \\
\hline & Idade & 0,011 & 0,000 & 0,746 & 0,002 \\
\hline & Renda Familiar & 0,059 & 0,003 & 0,224 & 0,000 \\
\hline & Ideologia & 0,085 & 0,007 & 0,048 & 0,079 \\
\hline & $\begin{array}{c}\text { Avaliação/Imagem } \\
\text { partido(esq/dir) }\end{array}$ & 0,045 & 0,002 & 0,309 & 0,039 \\
\hline
\end{tabular}

Fonte: ESEB, 2002, 2006. 
No que se refere à correspondência entre a avaliação de governo vigente e avaliação do PFL, o resultado mostrou-se estatisticamente significativo nos pleitos de 2002 e de 2006 (Sig. 0,000 e 0,003, respectivamente). Em 2002, foi detectada uma forte associação entre avaliar bem o governo Fernando Henrique e gostar do PFL e, em 2006, entre avaliar mal o governo Lula e gostar do PFL.

\section{Gráfico 10 - Avaliação de governo e avaliação do PFL 2002}

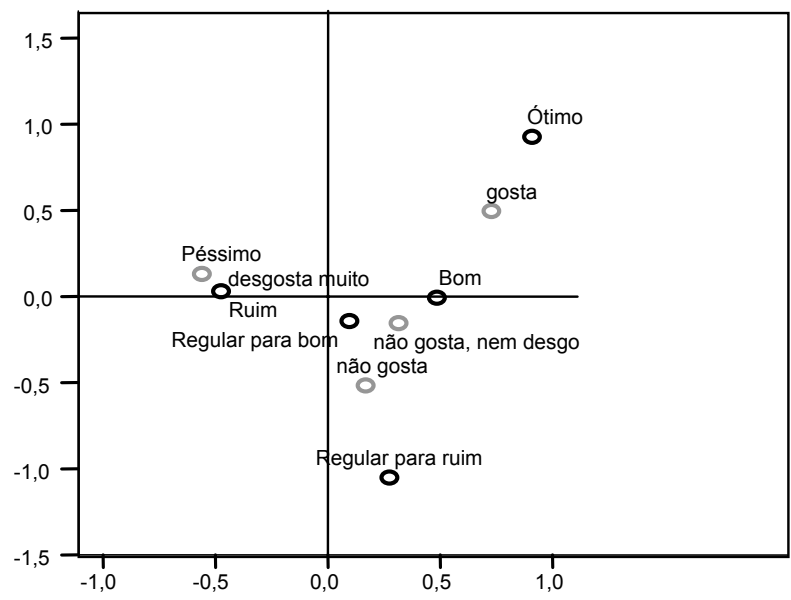

Avaliação do Governo

O Fernando Henrique nos últimos 4 anos

gostaPFLcat

Gráfico 11 - Avaliação de governo e avaliação do PFL, 2006

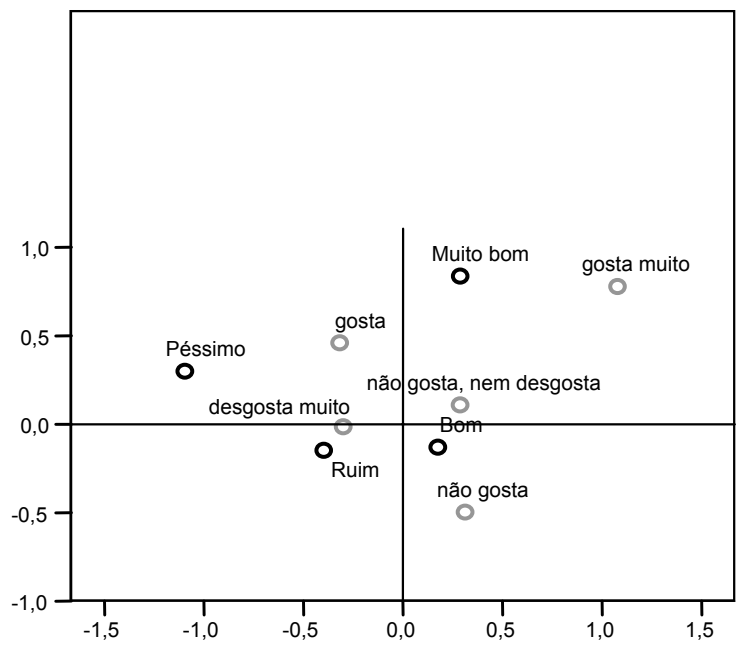

ESE6) Na sua opinião, de

uma maneira geral o

Governo Lula nos últimos

4 anos foi....

gostarPFLcat 
VEIGA, L. F. Os partidos brasileiros na perspectiva dos eleitores: mudanças...

Os resultados das análises de correspondência mostraram que existe por parte dos eleitores uma clara identificação dos partidos que ocupam os governos. Em 2002, PSDB e PFL estavam na situação e o PT na oposição. Naquela eleição, o PMDB, embora estivesse formalmente na chapa de José Serra, estava dividido. Em 2006, tem-se PSDB e PFL na oposição versus PT e PMDB na situação. A partir da avaliação que fazem da gestão em andamento, os eleitores aprovam ou desaprovam os partidos governantes. Como foi demonstrado, há correspondência entre avaliar bem o partido que está no governo e gostar do partido da situação e/ou avaliar mal o partido que está no governo e gostar do partido da oposição. Assim, continuamos apostando no conceito de identidade partidária proposto por Fiorina. Aliás, foi observado que a correspondência entre avaliar bem o governo e gostar do partido da situação foi mais constante do que as diversas correlações apresentadas nos dois pleitos e no estudo dos diferentes partidos.

\section{Considerações Finais}

Analisamos o perfil do eleitor que tem identificação partidária com um dos quatro grandes partidos brasileiros da atualidade e, especificamente, mapeamos mudanças e continuidades nesse perfil após quatro anos de governo Lula, principal liderança do PT desde a sua origem.

Os resultados da pesquisa apontam que houve uma redução no número de eleitores com identidade partidária com algum dos quatro grandes partidos. A maior perda na taxa de identificação partidária foi sentida pelo PT, mas nenhum dos três outros grandes partidos se beneficiou diretamente da perda petista.

Os dados sobre o perfil dos eleitores com identidade partidária contrariam e ao mesmo tempo se aproximam dos resultados encontrados por Dalton (2002) ao analisar as nações com estabilidade democrática e avanços econômicos. Diferentemente do que fora encontrado por Dalton, no Brasil, nos últimos quatro anos, a identidade partidária não caiu entre os mais jovens. Pelo contrário, em 2006, foi justamente o eleitorado mais novo que manifestou possuir uma identidade partidária. Já no que se refere à taxa de escolaridade, também em 2006, o caso brasileiro se aproximou da análise do autor: os eleitores que manifestaram possuir identidade com um dos quatro grandes partidos foram aqueles com menor escolaridade.

Esta redução no nível de escolaridade, em grande parte, está relacionada com a mudança do perfil do eleitor que se identifica com o PT. De 2002 para 2006, o partido despertou a identidade dos eleitores menos escolarizados. Antes de Lula assumir a Presidência, a maior parte dos eleitores que se identificavam com a legenda tinha escolaridade até o segundo grau. Agora, a maior parte do segmento 
desses eleitores é de analfabetos ou com primário incompleto. Seguindo a mesma tendência, a renda mensal dos eleitores que se identificavam com o PT em 2002 era de RS1.349,63 e foi reduzida para $\mathrm{R} \$ 985,08$ em 2006. Quanto à distribuição regional, o partido cresceu na região nordeste e perdeu força na região sudeste. $A$ última alteração diz respeito à postura ideológica. Em 2002, quando perguntados sobre sua auto-localização na escala esquerda (0) - direita (10), os eleitores que se identificavam com o PT inseriam-se no ponto médio de 4,7. Em 2006, o ponto médio passou para 5,5.

Essa transformação no perfil do eleitor que se identifica com o PT pode estar relacionada com a perda de parte do segmento mais ideológico e mais intelectualizado entre os simpatizantes, pois muitos seguiram os seus líderes e se transferiram também para o PSOL, e a adesão de um segmento novo do eleitorado, beneficiário dos programas sociais e das políticas de inclusão.

A respeito desse segundo ponto, para além das análises que creditam o sucesso eleitoral de Lula em 2006 aos programas e iniciativas implementados ao longo de seu governo para a população de classe baixa, Nicolau e Peixoto (2007), em estudo sobre as bases municipais na eleição de 2006, concluíram que:

“1. Em 2002, Lula tem votação bem distribuída pelo país, mas proporcionalmente melhor nas áreas mais desenvolvidas.

2. Ao longo do mandato, o Governo implementa uma série de programas dirigidos às cidades com menor desenvolvimento social. Entre esses programas, destaca-se o Bolsa Família que investiu mais de 17 bilhões em quatro anos, mais da metade deles no Nordeste.

3. Em 2006, as áreas que mais se beneficiaram das políticas implementadas pelo Governo Federal (particularmente municípios de baixa renda, majoritariamente concentrados nas Regiões Norte e Nordeste) votam no candidato que implementou essas políticas". (NICOLAU e PEIXOTO, 2007, p.14)

As razões para as mudanças no perfil dos eleitores do PT merecem um estudo a parte. No momento, são apenas hipóteses.

O PMDB, segundo partido a obter maior número de simpatizantes, também experimentou significativas mudanças no perfil dos eleitores que se identificam com a legenda. De 2002 a 2006, nota-se o aumento da escolaridade e da renda familiar entre os eleitores com identidade com o partido de Ulysses Guimarães. Em termos regionais, os dados apontam para o enfraquecimento da legenda no nordeste e para o seu fortalecimento no sul do país. Essa região e o sudeste seriam agora os redutos do PMDB. Já no que se refere à ideologia, nota-se uma maior proximidade com a esquerda entre os eleitores peemedebistas. Em 2002, o ponto médio da classificação do eleitor por ele mesmo na escala ideológica era 8,3, passando para 
o ponto médio de 6,3 em 2006. Ao que tudo indica, PT e PMDB parecem trilhar pelo mesmo caminho, mas em sentidos opostos.

Mudanças menores foram percebidas entre os eleitores que se identificam com o PSDB e o PFL. Os eleitores que se identificam com o PSDB são os com maior nível de escolaridade e de renda. Em termos regionais, o partido tinha, em 2002, como redutos o sudeste e o nordeste; em 2006, manteve-se forte no sudeste, mas a sua força no sul superou o apoio recebido no nordeste. Ideologicamente, parece que esse grupo tem a intensidade que mais se aproxima do eleitor identificado com o PT, o ponto médio na escala esquerda e direita era 6,5 em 2002 e 5,7 em 2006.

O perfil dos eleitores que se identificam com o PFL mudou pouco entre 2002 e 2006. Atualmente, o PFL é a legenda com a qual os eleitores que se reconhecem como de direita no espectro ideológico se identificam.

Assim, corroborando a proposição de Fiorina (1981), foi possível perceber alterações significativas entre 2002 e 2006 no perfil dos eleitores que manifestaram identidade com os partidos situacionistas PT e PMDB. As alterações no perfil dos eleitores que se identificaram com o PSDB e o PFL foram menores.

Também buscamos entender a relação dos partidos com a grande maioria do eleitorado que não manifesta identidade ou preferência por qualquer partido. Partimos do princípio de que ainda que os eleitores não tenham uma relação mais próxima com os partidos, de alguma maneira eles fazem uma imagem dos mesmos. De acordo com Sartori, os eleitores utilizam-se dessas imagens - mesmo que vagas e superficiais - ao tomarem as suas decisões políticas. Por isso, buscouse analisar não apenas a identidade partidária, mas também a avaliação da imagem dos partidos entre os eleitores.

Nossa pergunta central foi como os eleitores avaliam os quatro principais partidos? As notas médias foram: PT $(4,7), \operatorname{PMDB}(3,6), \operatorname{PSDB}(3,5)$ e PFL $(2,9)$. Todos os partidos receberam uma nota aquém daquela obtida pela primeira rodada da pesquisa em 2002.

Também perguntamos quais variáveis estariam relacionadas com as avaliações. Para isso, foram utilizadas análises estatísticas para verificar o peso e a relação entre a avaliação dos partidos e idade, renda familiar, ideologia do eleitor (auto-localização na escala esquerda-direita), imagem do partido na escala esquerda e direita e avaliação do governo.

A avaliação do governo vigente, a avaliação da imagem do partido na escala esquerda e direita e a ideologia do eleitor mostraram-se mais correlacionadas com a avaliação do partido do que as variáveis idade e renda familiar.

A partir da quantificação das relações, verificamos que a imagem que os eleitores têm dos partidos na escala esquerda e direita é mais determinante na avaliação da legenda do que a ideologia do eleitor. 
Nesse aspecto, vale chamar a atenção para a importância conferida pelos eleitores à imagem moderada do PT nas eleições de 2002 e 2006 para a avaliação do partido.

Por fim, destacamos a constante correspondência entre a boa avaliação do governo vigente e a boa avaliação do partido situacionista. Essa variável parece ter a melhor relação com a avaliação dos partidos. 


\section{Referências Bibliográficas}

CARREIRÃO, Y. e KINZO, M.D. "Partidos Políticos, Preferência Partidária e Decisão Eleitoral no Brasil (1989/2002)." Dados - Revista de Ciências Sociais, Rio de Janeiro, vol.47, n.1, p.131 a 168, 2004.

CAMPBELL, A. et al. The American Voter. New York: Wiley, 1960.

DALTON, R. The decline of party identifications. In: DALTON, R. e WALLTENBERG, M. Parties without partisans: political change in advanced industrial democracies. Oxford University Press, 2002.

DALTON, R. e WATTENBERG, M. Parties without partisans: political change in advanced industrial democracies. Oxford University Press, 2002.

DOWNS, A. An economic theory of democracy. New York: Harper Row Publishers, 1957.

FIORINA, M. Retrospective voting in American national elections. New Haven: Yale University Press, 1981.

KEY, V.O. Politics, Parties and Pressure Groups. New York: Crowell, 1964.

NICOLAU, J. e PEIXOTO, V. "Uma disputa em três tempos: uma análise das bases municipais das eleições presidenciais de 2006." Anais do 31 Encontro da Anpocs, Caxambu-MG, 2007.

SILVA, C. A. A lógica da análise de correspondência, 2003. Disponível em: <http://evunix.uevora.pt/ casilva/txt/cs cor.html>

VEIGA, L. F. et al. "As estratégias de retórica na disputa pela Prefeitura de São Paulo em 2004: PT, mandatário, versus PSDB, desafiante." Revista Opinião Pública, Campinas, vol.13, $n^{\circ} .1$, p.51-73, jun. 2007. 